\title{
O Elemento Sócio-Histórico e a Administração: Cornelius Castoriadis e a Literatura de Jorge Amado
}

\section{The Socio-Historical Element and Administration: Cornelius Castoriadis and Jorge Amado's Literature}

João Gualberto M. Vasconcellos ${ }^{1}$

Universidade Federal da Bahia / Escola de Administração, Centro Interdisciplinar de Desenvolvimento e Gestão Social (CIAGS/EA/UFBA), Salvador - BA, Brasil

Eduardo P. B. Davel ${ }^{2}$

Universidade Federal da Bahia / Escola de Administração, Centro Interdisciplinar de Desenvolvimento e Gestão Social (CIAGS/EA/UFBA), Salvador - BA, Brasil

\begin{abstract}
Resumo
O propósito deste estudo é examinar, apresentar e discutir a produção teórica de Cornelius Castoriadis, para enriquecer a análise organizacional dentro da esfera da Administração. Ao recuperar, sistematizar e discutir os principais conceitos da obra de Castoriadis, nossa pesquisa instiga a construção de um pensamento mais complexo, denso e dinâmico, apoiado principalmente no conceito do sócio-histórico. Isso é mobilizado no contexto da sociedade brasileira, de suas organizações e de seus padrões de gestão por meio do romance Gabriela, cravo e canela, um dos livros mais populares de Jorge Amado. A metodologia baseia-se na análise discursiva e na ficção como fontes inestimáveis de produção de conhecimento. O enfoque interpretativo recai sobre três campos: a sociedade, as organizações e a Administração.
\end{abstract}

Palavras-chave: Dinâmica sócio-histórica. Ficção. Administração no Brasil. Cornelius Castoriadis. Jorge Amado.

\begin{abstract}
The purpose of this study is examining, introducing, and discussing the theoretical works by Cornelius Castoriadis, in order to enrich organizational analysis within the sphere of Administration. By retrieving, organizing, and discussing the main concepts of Castoriadis' work, our research pushes the construction of a rather complex, dense, and dynamic thought, mainly supported by the socio-historical concept. This is mobilized in the context of Brazilian society, its organizations, and its management standards through the novel Gabriela, Clove and Cinnamon, one of the most popular books by Jorge Amado. Methodology is based on discursive analysis and fiction as invaluable sources of knowledge production. The interpretive focus lies on three fields: society, organizations, and Administration.
\end{abstract}

Keywords: Social-historical dynamics. Fiction. Administration in Brazil. Cornelius Castoriadis. Jorge Amado.

Artigo submetido em 3 de outubro de 2013 e aceito para publicação em 27 de maio de 2015.

DOI: http://dx.doi.org/10.1590/1679-395111841

Esta pesquisa contou com o apoio do Conselho Nacional de Desenvolvimento Científico e Tecnológico (CNPq) e com sugestões preciosas de avaliadores anônimos. Somos muito gratos a ambos.

${ }^{1}$ Doutor em Sociologia pela Ecole des Hautes Études en Sciences Sociales, França; Professor colaborador no CIAGS/EA/UFBA. Endereço: Avenida Reitor Miguel Calmon, s/n, Vale do Canela, CEP 40110-100, Salvador - BA, Brasil. E-mail: joaogualbertovasconcellos@gmail.com

2 Ph.D. em Administração pela École des Hautes Études Commerciales de Montreal (HEC Montréal), Canadá; Professor na CIAGS/EA/UFBA. Endereço: Avenida Reitor Miguel Calmon, s/n, Vale do Canela, CEP 40110-100, Salvador - BA, Brasil. E-mail: davel.eduardo@gmail.com 


\section{Introdução}

Nesta pesquisa, buscamos problematizar e discutir a importância da dimensão sócio-histórica ${ }^{3}$ como elemento teórico capaz de nos ajudar a melhor compreender a Administração enquanto campo de conhecimento no Brasil. Nesse sentido, o propósito é explorar um arcabouço conceitual que nos ajude a melhor apreender os elementos mais relevantes da construção social das instituições imaginárias sobre as quais repousam nossas práticas administrativas. Por sua importância intelectual e seu caráter explicativo inovador, o locus teórico da pesquisa é a contribuição intelectual de Cornelius Castoriadis para as Ciências Sociais, em especial para a Administração. A teorização na obra de Castoriadis é avançada no que se refere à integração de diversas tradições do conhecimento, bem como a sofisticação de suas proposições conceituais. Apesar de avançada e sofisticada, essa teorização ainda é timidamente mobilizada no campo da Administração e dos Estudos Organizacionais (VASCONCELLOS, 2002; KOMPOROZOS-ATHANASIOU e FOTAKI, 2014; DE COCK, REHN e BERRY, 2013).

Um aspecto fundamental da obra de Castoriadis é a consideração da dimensão histórica, ao afirmar que as instituições nascem e se desenvolvem no campo sócio-histórico. Assim, toda análise que não leve em conta sua historicidade porta um grave defeito de origem. Afinal, o tempo cria e recria as instituições. Do ponto de vista do imaginário social, as instituições são datadas. Dito de outra forma, elas são o tempo e portam o tempo. Nossa pesquisa se coloca, portanto, como um contraponto à tendência da perda da consciência histórica e do império do imediatismo, que caracterizam a Administração da atualidade (CHANLAT, 1999), empobrecendo tanto a prática como a pesquisa organizacional.

Partimos do princípio de que é possível compreender mais profundamente as bases que sustentam a instituição da Administração na sociedade brasileira, tendo como base a formulação intelectual do filósofo político grego Cornelius Castoriadis (1922-1997), em especial aquela que trata do imaginário social e do sócio-histórico. Entendemos que nosso olhar será realizado em um plano macrossocial, mas que se olhássemos a partir de uma perspectiva microssocial ou de forma localizada, seria necessário considerarmos as diferenças entre regiões, entre tipos de organizações, entre setores da economia e assim por diante. Como a comunhão dessas duas perspectivas inviabilizaria a extensão deste artigo, partimos do entendimento macrossocial que de existe uma cultura brasileira instituída por nosso imaginário social e que a Administração como instituição imaginária está imersa nessa cultura. Empreendedores jovens ou antigos, gestores públicos ou privados, todos são, de alguma forma, impregnados e alimentados pelo passado instituído.

Para alcançar seu objetivo, este artigo foi estruturado em quatro partes, além desta introdução. A primeira parte apresenta ideias e conceitos de Cornelius Castoriadis que servirão de caminho interpretativo para a compreensão da dimensão sócio-histórica da Administração no contexto brasileiro. A segunda parte discute o método baseado na literatura e na escolha de Jorge Amado (1912-2001) - autor que demonstrou ser um observador atento da sociedade brasileira de sua época. Foi capaz de retratar nossa construção imaginária social com primor e sutileza. Sua força elucidativa se faz maior ainda pela importante adesão às suas análises. Afinal, trata-se de um dos mais populares romancistas brasileiros, cujos textos estão, pode-se dizer, legitimados socialmente. A terceira parte do artigo analisa a obra Gabriela, cravo e canela de Jorge Amado, enfocando o protagonista Mundinho Falcão. Â luz do pensamento castoriadiano, refletiremos sobre as significações imaginárias e a dimensão sócio-histórica da Administração no contexto brasileiro. Finalmente, por se tratar de um trabalho de cunho exploratório serão feitas algumas propostas teórico-metodológicas a ser consideradas em pesquisas futuras.

\footnotetext{
${ }^{3} \mathrm{Na}$ teoria de Cornelius Castoriadis, o termo utilizado é "social-histórico", inclusive na tradução em língua portuguesa. Neste artigo, decidimos alterar para "sócio-histórico" para facilitar a compreensão e o diálogo dentro do campo de estudos sobre a perspectiva histórica da administração.
} 


\section{Castoriadis: Um Pouco de sua Trajetória}

Antes de mergulharmos em sua obra teórica, é necessário contextualizar a trajetória intelectual e de vida do filósofo grego, Cornelius Castoriadis. A intenção é situar o leitor acerca de suas ideias. O objetivo maior é o de facilitar a compreensão da produção, colocando em evidência o valor de seu trabalho. Vamos começar com uma citação que expressa muito bem uma de suas ideias mais fortes:

É, pois, impossível manter uma distinção intrínseca do social e do histórico... O social é isso mesmo, autoalteração, e nada é senão isso. O social faz-se e só pode fazer-se como história... O histórico é isso mesmo, autoalteração desse modo específico de 'coexistência' que é o social e nada fora disso (CASTORIADIS, 1982, p. 252).

Castoriadis nasceu em Constantinopla, em 1922, mas passou sua infância em Atenas. A mudança de cidade se deu porque seu pai temia que o exército grego, que estava na Ásia Menor, pudesse ser vencido pelos turcos, o que resultaria em enfrentamentos entre Grécia e Turquia ${ }^{4}$. Por essa razão, a família mudou-se para a Grécia alguns meses depois de seu nascimento. Em função de sua educação familiar, ele sempre valorizou o ideal democrático, seguindo os princípios paternos. Com 13 anos, começou a ler apaixonadamente filosofia e marxismo, definindo precocemente o direcionamento de sua vida. Mais tarde, já na universidade, filiou-se ao Partido Trotskista grego.

Quando a Escola Francesa de Atenas ofereceu a oportunidade de bolsas de estudo na França, ele, que já havia terminado os cursos de direito e ciências econômicas e políticas, candidatou-se na categoria de estudos filosóficos e foi aprovado. Na França, fez doutorado em Filosofia na Sorbonne e depois teve longa militância entre trotskistas. Fundou, inicialmente, com Claude Lefort, a revista Socialismo ou Barbárie, importante publicação de esquerda entre os anos de 1946 e 1965. Vê-se, claramente, nos escritos da revista, por meio dos anos, seu progressivo afastamento das ideias marxistas.

Depois, teve importante participação intelectual no Maio de 1968. Já distante do marxismo, publicou em 1975 de sua obra maior, intitulada A Instituição Imaginária da Sociedade. Intelectual já respeitado e com produção amplamente reconhecida, Castoriadis foi professor na École des Hautes Études en Sciences Sociales (Paris), a partir dos anos 1980. Autor de vários livros, dentre os quais se destacam os seis volumes de As Encruzilhadas do Labirinto, publicados entre 1978 e 1999; o último após sua morte em 1997.

Em toda a trajetória intelectual de Castoriadis o que se vê são as marcas de um homem dedicado à questão da democracia como um processo que se cria e recria constantemente. O pensador não se ateve, em sua obra, às análises simplificadoras, não deu destaque a partidos, eleições ou quaisquer outras instituições comumente analisadas na sociologia. Ao contrário, deteve-se em aspectos mais profundos do ponto de vista filosófico, com especial destaque para o conceito de imaginário social e de sócio-histórico (KLOOGER, 2009; JOAS e MEYER, 1989; CURTIS, 1997).

\section{O Sócio-Histórico na Teoria de Castoriadis}

Para entendermos o fundamento da teoria de Castoriadis, é preciso compreender que, segundo ele, a construção do mundo próprio por cada sociedade é, na essência, criação de um mundo de significações. Ou seja, são as significações imaginárias sociais que organizam o mundo natural e instalam o mundo social próprio de cada sociedade. Elas estabelecem as formas como os indivíduos são humanizados e socializados,

\footnotetext{
4 Informações obtidas em entrevista disponibilizada no site Agora Internacional e concedida por Castoriadis em 1990, no Colóquio de Cerisy.
} 
como são socialmente produzidos. Instituem os motivos, valores e hierarquias da vida social. A sociedade se apoia, é certo, sobre o primeiro estrato natural, mas para erigir um edifício de significações fantasticamente complexo que investe tudo de significação (CASTORIADIS, 2004).

As significações são denominadas de imaginárias porque elas não correspondem e nem se esgotam em elementos racionais ou "reais" e também porque são introduzidas por uma criação. São denominadas de sociais, pois somente existem enquanto são instituídas e compartilhadas por um coletivo impessoal e anônimo. As significações fazem tudo existir e por isso podem ser entendidas como princípio de existência, de pensamento, de valor e de ação (CASTORIADIS, 2002a). "É só relativamente a essas significações que podemos compreender, tanto a 'escolha' que cada sociedade faz de seus simbolismos, e principalmente de seu simbolismo institucional, como os fins aos quais ela subordina a "funcionalidade" (CASTORIADIS, 1982, p. 177).

Outro conceito chave é o de "sócio-histórico", entendido como a relação entre o indivíduo e a sociedade. Para Castoriadis, os relatos da sociedade e da história não podem ser entendidos quando vistos exclusivamente por meio de uma dessas dimensões. Ou seja, não existe um indivíduo isolado; ele é sempre produto social, mas não se reduz ao social. Uma tensão entre o psíquico e a sociedade é sempre imanente. É necessário entender o conceito de sócio-histórico como fluxo perpétuo de autoalteração, que se torna visível à medida que vai criando figuras estáveis. A figura estável para ele é a instituição ou uma instituição. Assim, antes de ser instituição explícita do tempo, constituição de um tempo identitário submergido em um magma de significações imaginárias, ele próprio - o sócio-histórico - é instituído como tempo imaginário. Por isso, é criação permanente. O sócio-histórico deve ser entendido como criação e é dessa criação circular permanente que nascem os processos verdadeiramente revolucionários em uma sociedade determinada (CASTORIADIS, 1982).

O sócio-histórico como criação requer a consideração do caráter indeterminado da vida social e histórica. Trata-se de uma compreensão baseada na relação entre sociedade e o psíquico, que se encontram, ao mesmo tempo "em relação de conflito e complementaridade, engajando frequentemente em uma cooperação carregada e tensa, dentro de uma acomodação tênue que nunca resulta em um estado de paz e harmonia definitivo" (KLOOGER, 2009, p. 9). Nesses termos, o conflito é essencial em todos os sistemas sociais, mas também o é a criatividade, na medida em que a mudança sempre emerge da criação por meio do posicionamento de novos significados.

Importante também é conceito de "Magma de Significações Imaginárias Sociais". Ele equivale ao de um rio em movimento, onde indivíduos e sociedades se banham para se autoinstituírem. O magma é a fonte que permite a criação infinita de organizações, mas que não pode ser reconstituído pelas organizações, pois as ultrapassa em complexidade (CASTORIADIS, 1982. É um tecido coeso e complexo em significações que impregnam, orientam e dirigem a vida social e os indivíduos que a constituem e a animam. São exemplos de significações imaginárias sociais os espíritos, os deuses, Deus, o Estado, a mercadoria, o dinheiro, o capital, a virtude, o pecado, a criança, o homem, a mulher (CASTORIADIS, 2002).

Para elucidar um fenômeno social na perspectiva que estamos adotando, ou seja, na dimensão sócio-histórica de determinada sociedade, e, por conseguinte, em todo e qualquer tipo de organização nela contida, é necessário se valer da reflexão sobre o processo de autoinstituição dessa mesma sociedade. Para Castoriadis, existe uma sociedade instituinte e uma sociedade instituída, que se relacionam de forma umbilical, indissociável, criativa (JOAS e MEYER, 1989). Essa é uma das chaves interpretativas mais importantes para entender o elemento sócio-histórico, que é uma unidade que se autoinstitui e se autotransforma e que não pode ser reduzido ao físico, biológico ou mesmo ao psíquico. "A sociedade instituída não se opõe à sociedade instituinte como um produto morto a uma atividade que o originou" (CASTORIADIS, 1982, p. 416). Portanto, temos que levar sempre em conta a dinâmica sócio-histórica, responsável pela inseparável tensão criativa. Toda criação implica, logo, em fluxo e refluxo. O instituído também institui como se fosse uma via de mão dupla. 
Levando em conta essa formulação, a história não pode ser concebida dentro de nenhum esquema tradicional de sucessão. $\mathrm{O}$ que se dá na história e pela história não é sequência determinada do determinado, mas emergência da alteridade radical, criação imanente, novidade não trivial. A história é o que se manifesta no aparecimento de novas sociedades, de novos tipos de sociedades e na autotransformação incessante de cada sociedade. Somente a partir dessa alteridade radical ou criação é que se pode pensar verdadeiramente a temporalidade e o tempo, cuja efetividade encontra-se na história. O tempo verdadeiro é aquele em que há alteridade (CASTORIADIS, 1982).

Cada sociedade cria um tempo imaginário para si, ou seja, cria o seu próprio tempo imaginário. Na perspectiva adotada por Castoriadis, cada sociedade tem sua maneira própria de viver o tempo, mas cada sociedade é também uma maneira de fazer o tempo. Por exemplo, a alteridade separa a temporalidade efetiva do capitalismo daquela temporalidade da maioria das sociedades arcaicas. Primeiro, na instituição explícita do tempo que fazem essas sociedades, a relação entre tempo identitário (tempo de referência, tempo de calendário) e o tempo de significação (tempo imaginário) não é a mesma. O tempo identitário é o tempo das medidas, mas o tempo instituído como socialmente imaginário é o tempo da significação. Nesse sentido o tempo é inseparável do ser e inseparável das instituições imaginárias de cada sociedade.

Tempo e criação estão intimamente ligados no pensamento de Castoriadis. O tempo não é o supérfluo ou repetição em ciclos. Para Castoriadis, a criação deve ser pensada de uma forma nova e inovadora, já que ela torna-se impossível no pensamento herdado. É criação ontológica, aquilo pelo qual existe o outro e não simplesmente o idêntico. $\mathrm{O}$ tempo deve ser percebido como autoengendramento da alteridade absoluta.

Em sua antítese e em olhar mais profundo, no ser, no "por-ser", emerge o sócio-histórico. Ele próprio como ruptura do ser e instância de aparição da alteridade. O sócio-histórico é imaginário radical, a saber, a origem incessante de alteridade. O sócio-histórico é estabelecimento de figuras e relação com essas figuras. Comporta sua própria temporalidade como criação, essa temporalidade sócio-histórica (CASTORIADIS, 1982). A história é autodesdobramento da sociedade no tempo, ela não ocorre à sociedade. Ela é, em si, seu autodesdobramento.

A partir do que já foi registrado, podemos concluir que todo conjunto bem articulado de ideias comporta uma leitura do social, denominada de sócio-histórico. Ao adotar a expressão "sócio-histórico", Castoriadis procura a unidade da dupla multiplicidade de dimensões - indivíduo e sociedade - na simultaneidade e na sucessão que habitualmente denotam os termos sociedade e história. Todavia, o sócio-histórico não é nem uma adição indefinida dos entrelaçamentos intersubjetivos nem seu simples produto.

O sócio-histórico refere-se ao coletivo anônimo, ao humano-impessoal que preenche toda formulação social dada, englobando-a, inserindo cada sociedade entre as outras e as inscrevendo em uma continuidade, onde, de certa maneira, estão presentes os que não existem mais, os que estão ausentes e mesmo os que estão por nascer. De um lado, representa as estruturas dadas, instituições e obras concretas, sejam elas materiais ou não. De outro lado, representa o que estrutura, institui, materializa. Em suma, é ao mesmo tempo união e tensão da sociedade instituinte e da sociedade instituída, da história feita e da história se fazendo.

Nessa visão, cada sociedade é autocriação: cria suas significações, suas formas institucionais e suas leis. Cada uma é resultado da capacidade coletiva anônima. É capacidade do imaginário social instituinte de criar linguagem, costumes, ideias, formas de família, etc. (CASTORIADIS, 1982). Cada uma é, nesse sentido, sócio-histórica. Depois de criadas, as instituições sociais aparecem como dadas. Podem se tornar fixas, rígidas, sagradas, fábricas de indivíduos cujas representações psíquicas, afetos e intenções repetem as significações sociais instituídas.

\section{A Administração no Brasil pelas Lentes do Sócio-Histórico}

Para Castoriadis, cada sociedade se autoinstitui e institui também seu tempo imaginário e suas significações imaginárias sociais. Ela é, portanto, única e é assim que tem que ser entendida. Por essa razão, os esquemas 
interpretativos genéricos e universais são insuficientes para explicar o que se passa em um lugar específico. Quando se utilizam os conceitos mais gerais, sem enraizamento local, estamos trabalhando na dimensão conjuntista-identitária, que não deixa de ser importante, mas não é suficiente para explicar com propriedade o todo. Por isso, a perspectiva de Castoriadis torna-se relevante, pois coloca em destaque as dimensões singulares de determinada sociedade. No caso da Administração, que é uma prática social cotidiana e datada, sujeita aos humores do tempo e de todas as subjetividades, é quase impossível avançar em sua compreensão sem levar em conta a história das instituições da sociedade na qual se situa, bem como a tensão criativa que se estabelece entre indivíduo e sociedade. Afinal, é no social e na história que a sociedade se cria, e cria suas instituições imaginárias. Propomos que o campo da Administração deve ser compreendido como uma instituição imaginária, articulada pelo sócio-histórico.

Toda a leitura da administração comporta uma compreensão histórica (REED, 1996; FERREIRA, 2008); uma compreensão da dimensão sócio-histórica. Temos que entendê-la como criação imaginária de certa sociedade, como parte de seu imaginário profundo. A partir do referencial de Castoriadis, não devemos nos limitar somente às representações, ao espetacular, à imagem refletida (de acordo com as correntes psicanalíticas), ao reflexo, ao fictício. O imaginário é criação permanente, sócio-histórica, psíquica de figuras, formas e imagens, produzindo realidade e racionalidade (CASTORIADIS, 1982). "As instituições e as significações imaginárias sociais são criações do imaginário radical, do imaginário social instituinte, da capacidade criadora da coletividade" (CASTORIADIS, 1992, p. 158-159).

A administração das organizações de uma sociedade é criação do imaginário social instituinte, portanto é instituída pelo coletivo anônimo. Trata-se de criação, intimamente ligada a rede de instituições imaginárias dessa sociedade. Dessa forma, seria impossível, para fins analíticos, separar as dinâmicas da sociedade das dinâmicas de Administração. No entanto, quando princípios e práticas de administração de uma sociedade se aplica a outra podem haver problemas. De acordo com o conceito de sócio-histórico em Castoriadis, tentar aplicar preceitos de uma sociedade - como se faz com modelos de gestão, sobretudo os americanos (VERGARA, 2001) - a outra sociedade distinta reflete uma postura conjuntista-identitária. Ao assim proceder, a análise volta-se para uma simplificação que despe o objeto do conjunto de sua complexidade, de suas nuanças e sutilezas.

O sócio-histórico refere-se ao coletivo dinâmico que preenche e engloba toda a sua formação social, inscrevendo-a na sociedade, na sua tensão criativa, no seu fio condutor. Faz isso ao estruturá-la, instituí-la, dinamizá-la e materializá-la. Afinal, o sócio-histórico é união e tensão entre sociedade instituinte e instituída, entre história feita e a que se está fazendo (CASTORIADIS, 1982). A dinâmica que se institui com o elemento sócio-histórico provoca uma relação circular. Ou seja, se de um lado estamos tratando de saberes e práticas que se apropriam de significações imaginárias sociais já instituídas, de outro o instituído influencia e é influenciado pelo instituinte.

A mesma lógica analítica pode ser aplicada à Administração e às organizações. Processos e estruturas administrativas são instituídos socialmente, mas também terminam por instituir outros comportamentos, estilos e padrões administrativos. Importar e aplicar modelos sem uma análise do sócio-histórico, portanto, é uma ação que corre o alto risco de descolar uma instituição de seu imaginário social. O desconhecimento do papel estruturante da dinâmica sócio-histórica pode gerar problemas sérios de análise organizacional e ter consequências drásticas em matéria de efetividade do trabalho coletivo, desempenho de atividades laborais e coerência cultural.

A administração como área de estudos e como prática social está fundada em uma sociedade que se cria - se institui - ao longo de duas dimensões tecidas conjuntamente: a dimensão conjuntista-identitária (conídica) e a dimensão propriamente imaginária (poiética) (CASTORIADIS, 1992). Apoiar-se em uma só delas, é ver a metade da verdade. A dimensão conjuntista-identitária refere-se a classes, propriedades, relações como postulados distintos, definidos, bem determinados. Por sua vez, a dimensão imaginária refere-se a significações, que, ao invés de ser determinadas, distintas e definidas, são demarcadas (CASTORIADIS, 1992). 
Quando a Administração enquanto campo de conhecimento é construída de acordo com uma visão conjuntista-identitária tende a ignorar a dimensão imaginária e limitar sua análise à parcialidade. Durante a produção e aplicação de conhecimentos administrativos, com frequência, esquecemos que as questões determinantes que influenciam a gestão das organizações, sejam elas públicas ou privadas, não nascem apenas dentro deles, mas alimentam-se da sociedade como um todo. Nenhuma organização é implantada em determinado espaço, em determinado tempo social. Ela também nasce dele e está imbricada com ele. Ela está necessariamente envolvida pelo ambiente, pela dinâmica sócio-histórica. Elas não dependem apenas do desejo e conhecimentos técnicos dos administradores, mas de toda uma malha de instituições sociais imaginarias. Torna-se, portanto, impossível compreender a Administração descolada da dinâmica sóciohistórica, dos elementos que a produzem e que são também produzidos por ela, dentro da tensão criativa que se instala no âmago de cada sociedade.

No caso brasileiro, um elemento fundamental em nosso mundo do trabalho - instituição imaginária fundamental para apreender os padrões de Administração - é a produção da dinâmica sócio-histórica. Pensemos, então, o trabalho e o trabalhador como instituições imaginárias sociais. Existe uma produção social dos indivíduos, já que nenhum ser existe no vazio. O trabalhador existe e é produzido por determinada sociedade. Nessa produção estão presentes suas instituições imaginárias. São indivíduos socialmente produzidos que vão dar vida às organizações, conferindo-lhe dimensões subjetivas, humanas, dando aos comportamentos sua dimensão imaginária e sócio-histórica.

Dentro da perspectiva de Castoriadis, o coronel é um personagem que nos ajuda na dimensão imaginária e sócio-histórica do mundo do trabalho e da Administração no Brasil (VASCONCELLOS, 1995; 2002). É preciso pensar o coronelismo como instituição imaginária para desvendar o que se passa hoje, porque quando falamos em coronel, é importante frisar que não estamos falando do passado. Estamos, ao contrário, falando de uma instituição imaginária que atravessou os tempos e que continua presente no cotidiano, mesmo que sob outras facetas, mas que sempre se instala toda vez que se estabelece uma relação de poder. $\mathrm{O}$ coronelismo e o coronel podem se manifestar em nosso campo organizacional e administrativo. Desconsiderá-los, ao tratar das organizações e sua Administração no Brasil, pode representar riscos de recair sobre uma análise unidimensional, conjuntista-identitário. Ou seja, refletir e propor ações administrativas a partir de apenas uma parte do "real", subestimando a dinâmica sócio-histórica.

Vamos pensar no processo histórico que criou a figura do coronel no contexto das instituições imaginárias no Brasil. Tivemos uma estrutura de poder local muito concentradora desde os tempos coloniais. A unidade produtiva de base no período inicial de nossa colonização foi o latifúndio. Deve-se a eles, em boa parte, a produção do que Faoro (1975) denominou de "potentados rurais". Seu poder estendia-se muito além daquele que provinha do domínio das terras. O próprio Estado português, por meio da estrutura das Milícias e Ordenanças, tratou de outorgar títulos de oficial dessas milícias aos potentados rurais. Criou-se, assim, uma camada social de homens que tudo podiam. Eram, a um só tempo, senhor de terras, oficiais de uma milícia armada e políticos que detinham o poder nos municípios.

Esse poder local exagerado era exercido sobre um conjunto de pessoas sem condições de defesa, porque eram, sobretudo, escravos. O mundo do potentado rural era o mundo da casa grande, brilhantemente descrito por Freyre (1966; 1968). Um mundo sem a noção de cidadania ou de respeito humano. A ausência de limites e a ausência de noção do outro foi a marca do processo brasileiro de colonização. Dentro dessa lógica de "senhor total" ou de "mestre da significação", o coronel tudo controlava, desde a vida política ao funcionamento econômico, passando pelo destino da vida das pessoas (VASCONCELLOS, 1995).

Em um processo histórico com poucas rupturas, onde o Império e a República foram obras das elites, tanto que a última ficou conhecida como a "República dos Coronéis", foram poucos os momentos de tensão criativa que puderam construir uma dinâmica sócio-histórica capaz de produzir novas instituições imaginárias. Nesse vazio, tivemos uma longa duração do velho. Isso, certamente, ajuda a explicar a sobrevivência do imaginário do coronel (VASCONCELLOS, 1995). É desse imaginário - calcado na figura do coronel - que ainda podemos encontrar expressões nas organizações e na Administração no Brasil. 
O coronelismo e o coronel como instituições imaginárias centrais na sociedade brasileira atingem o seu apogeu na chamada República Velha ou a "República dos Coronéis" situada entre o ano de seu surgimento em 1889 e o início na República Nova com o golpe de Getúlio Vargas em 1930 (VASCONCELLOS, 1995). Como articuladores mais importantes do projeto político das elites, sobretudo no nível do poder local, os coronéis transformaram-se nos atores centrais do processo de modernização econômica proporcionado pela proclamação da república.

Como expressão privilegiada, a ambiguidade dos coronéis republicanos era uma manifestação da dinâmica sócio-histórica. A um só tempo, os coronéis demonstravam ser modernos no avanço econômico e portadores dos padrões tradicionais de administração da força de trabalho, construído em nosso processo sóciohistórico. Violentos quando tratavam com as questões de honra, que deviam ser lavadas com sangue, mas, ao mesmo tempo, modernos na administração de seus empreendimentos. Nessa tensão, sempre presente entre o velho e o novo, entre o arcaico e moderno, ganham vida os coronéis, os administradores e os empreendedores desses tempos devido à existência de um forte mercado interno (CALDEIRA, 2009).

Políticos importantes como Jerônimo Monteiro - Governador do Estado do Espírito Santo entre 1908 e 1912 - grande modernizador da vida capixaba mas capitaneando processo político eivado de violência e fraudes, eram personagens comuns da época. Empreendedores e administradores, como o Coronel Delmiro Gouveia, precursor da moderna indústria, da agricultura em grande escala e do comércio nos moldes parisienses em Pernambuco e em Alagoas nos anos 1910, também eram representantes de um modus operandis administrativo típico da época (VASCONCELLOS, 1995).

A modernização econômica brasileira do início do século XX carregou em seu epicentro a lógica do coronel. O coronel, como empreendedor, introduziu no Brasil as novidades da administração dita científica (VASCONCELLOS, 2002), realizando a internacionalização de nossos modos de administração, entretanto, nunca abandonando suas práticas de poder alicerçadas nas práticas autoritárias do passado. Eram modernos, mas modernos à brasileira, com um forte pé na violência.

Como instituição imaginária, a Administração no Brasil é marcada pela dupla prática. De um lado, os preceitos da industrialização anglo-saxônica, como o respeito aos horários e as normas de higiene no trabalho. De outro, funcionários tratados literalmente no chicote. Pontualidade e chicote foram, sem dúvida, as marcas explícitas do processo de industrialização no Brasil (MOTTA, 1993; PAES DE PAULA, 2001; TRAGTENBERG, 1980). Marcas que impregnam nosso imaginário social e se expressam nos padrões de administração. São elementos significativos de nosso imaginário social instituinte. Entretanto, vale lembrar que, neste artigo, nos interessa demostrar como eles surgiram, como se afirmaram e como são fortes em nosso imaginário social. Para elucidar melhor esse processo histórico nos apoiaremos no campo da literatura, em especial aquela produzida pelo incontornável autor brasileiro: Jorge Amado. Nela, cremos ficar claro o argumento aqui desenvolvido.

\section{Metodologia: A Força da Literatura como Fonte Dinâmica de Conhecimento}

Na empreitada metodológica de elucidação da produção social do coronel como a instituição imaginária que institui a Administração na sociedade brasileira, estamos em busca, quando se trata de método de pesquisa, dos elementos que singularizam a nossa sociedade. O elemento sócio-histórico como um dos construtores do imaginário social será dificilmente encontrado em relatórios organizacionais ou nas fontes burocráticas de empresas. Um material histórico vivo, explicativo e com sutilezas descritivas exige outras formas de ser encontrado. Por isso, nossa fonte privilegiada de dados é a produção literária (PHILLIPS, 1995). Em especial, escolhemos o romance regional brasileiro, principal veio literário na primeira metade do século XX no Brasil, mas com forte expressão popular nas décadas posteriores. 
Dentre os importantes autores que compõem esse ciclo de produção literária encontram-se aqueles com a expressão de Érico Veríssimo, José Lins do Rego ou José Américo. Dentre eles, escolhemos o baiano Jorge Amado pela extraordinária repercussão na mídia de sua obra e consequentemente pelo seu enraizamento no imaginário popular. Vários são os filmes ou novelas de televisão adaptadas de seus inúmeros romances. Seus tipos são substantivamente representativos de um Brasil que o genial autor retratou.

Nossa inspiração para utilizar a literatura como elemento metodológico esclarecedor do imaginário social brasileiro baseia-se em sua relevância para facilitar o acesso do pesquisador qualitativo a fenômenos complexos, tanto no plano subjetivo, como sócio-histórico (CZARNIAWSKA-JOERGES e GUILLET DE MONTHOUX, 1994; PATIENT, LAWRENCE e MAITLIS, 2003; PHILLIPS, 1995). É fácil dizer que os pesquisadores que se apoiam em fontes de informação mais sutis tendem a melhor captar a complexidade do Real e gerar conhecimento de qualidade diferenciada. Como o que se pretende examinar a narrativa desenvolvida em um romance para entender algumas facetas do sócio-histórico e da construção imaginária da Administração no Brasil, é desse tipo de aporte metodológico que nos valeremos na análise e interpretação que realizaremos mais adiante.

Interessam-nos, em particular, obras literárias que tratem do universo da figura do coronel como empreendedor e administrador. Essa perspectiva leva em conta a lógica de Galvão (2010), que acredita que a literatura e a história não se opõem como discursos antagônicos. Pelo contrário, muitas vezes, elas se utilizam dos mesmos mecanismos para construir suas análises. Para Galvão (2010), as obras dos autores conhecidos como regionalistas estimulam essa perspectiva, uma vez que apresentam relatos que margeiam constantemente ficção e realidade, aproximando o coronelismo enquanto fenômeno social e histórico das fantasias e experiências pessoais de um narrador que não se exime de interferir nos rumos da narrativa que conduz.

\section{O Romance Gabriela, Cravo e Canela e o Imaginário Social da Administração}

A literatura nos mostra como, no início do século XX, as práticas administrativas modernas dos latifúndios chegaram ao Brasil e imbricaram-se com a nossa dinâmica sócio-histórica. Pode-se entender, a partir de romances importantes desse período, como os preceitos de Taylor ou Fayol foram sendo utilizados ao mesmo tempo que a violência no trato com o outro, nascidos na fase colonial, ainda continuavam presentes.

Uma obra literária onde esses aspectos aparecem fartamente presentes é a produção de Jorge Amado. Além de um magistral escritor, produtor de uma obra mundialmente conhecida, Jorge Amado foi um grande observador da vida social brasileira. Uma das características marcantes em sua análise é que ele levou muito em conta o caráter sincrético e, digamos, mulato, mestiço e miscigenado de seus personagens, construídos na sombra dos brasileiros. Elaborou personagens que retratam com maestria traços da cultura brasileira, inclusive do ponto de vista político. Alguns de seus protagonistas mesclam o tradicionalismo - violência, fraudes eleitorais, patrimonialismo - com elementos mais modernos e também mais humanos.

Em uma de suas obras mais conhecida, Gabriela, cravo e canela, publicada em 1958 - dentro do chamado ciclo do cacau - Jorge Amado retrata a construção e administração do progresso no sul da Bahia nos anos 1920, quando explodiu os empreendimentos da cultura do cacau. Neles, são significativamente importantes a construção dos personagens, atores sociais tão híbridos e tão marcados pela presença do futuro e do passado. Tudo em um só indivíduo.

Mundinho Falcão chegou a Ilhéus quando o novo mundo do cacau estava no auge e desempenhou o papel que várias personagens da vida real também desempenharam. De fato, na vida social brasileira, vários foram grandes personagens da política ou do mundo dos negócios que portaram o hibridismo que Jorge Amado tão bem descreve no principal personagem masculino de Gabriela, cravo e canela. 
Na verdade, Mundinho Falcão encarna o tipo ideal do administrador-empreendedor carregado de hibridismo. Ideias modernas, impulsividade, certa agressividade e um toque de romantismo. No romance, ele vai para Ilhéus esquecer uma paixão e acaba por se apaixonar, no fim da história, pela filha de seu maior rival político. Entretanto, ao longo da história ele mantém certa distância do machismo exacerbado nos demais personagens, embora também mantenha casos com dançarinas estrangeiras e outros tipos femininos contra os quais havia enorme preconceito em Ilhéus, cidade provinciana do romance. Entretanto, foi na condição de empreendedor visionário que ele ganha força dentro do romance.

Da ponte de comando do navio a espera de prático, um homem ainda jovem, bem vestido e bem barbeado, olhava a cidade com um ar levemente sonhador. Qualquer coisa, talvez os cabelos negros, talvez os olhos rasgados, dava-lhe um toque romântico, fazia com que as mulheres logo o notassem. Mas, a boca dura e o queixo forte eram de homem decidido, prático, sabendo querer e fazer. O comandante, rosto curtido pelo vento, mordendo um cachimbo, estendeu-lhe o binóculo. Mundinho Falcão disse, ao recebê-lo:

- Nem preciso... Conheço casa por casa, homem por homem. Como se tivesse nascido ali, na praia - apontava com o dedo. - Aquela casa - a da esquerda ao lado do sobrado - é minha casa. Posso dizer que essa avenida eu a construí...

- Terra de dinheiro, de futuro - falou, como conhecedor, o comandante. - Só que a barra é uma desgraça...

- Isso também vamos resolver - anunciou Mundinho. - E muito em breve...

- Deus lhe ouça. Toda a vez que entro aqui, temo pelo meu navio. Não há barra pior em todo o Norte.

Mundinho levantou o binóculo, aplicou-o aos olhos. Viu sua casa moderna, trouxera um arquiteto do Rio para construí-la.

[...] Mas essa não era uma terra qualquer. Ali crescia o cacau. Onde melhor aplicar o seu dinheiro, multiplicá-lo? Bastava ter disposição para o trabalho, cabeça para os negócios, tino e audácia. Tudo isso, ele possuía e algo mais: mulher a esquecer, paixão impossível a arrancar do peito e do pensamento (AMADO, 1960, p. 39-40).

Mundinho, apesar de seus pensamentos modernos, típicos de um jovem criado nos centros mais modernos da época e que teve contado com conceitos novos de administração, faz sua política em Ilhéus com pragmatismo, usando também elementos tradicionais: favores aos amigos, atenção dispensada aos aliados e negada aos rivais. Uma figura de estratégia, interessado em poder e prestígio, apesar de ser um empreendedor cheio de sonhos. Jorge Amado assim descreve esse aspecto no personagem:

- O coronel Altino Brandão... Vende sua safra esse ano a Mundinho.

E pode ser que negocie seus votos também... - mudava o tom de voz. - Por que diabo o jornal não está ainda circulando?

O coronel Brandão, do Rio do Braço... O maior fazendeiro da zona depois do coronel Misael. Com ele votava todo o distrito, era carta importante na vida política.

Clóvis Costa dizia a verdade. No escritório de Mundinho, afundado na poltrona de couro, macia, o fazendeiro, de botas e esporas, saboreava um licor francês, servido pelo exportador. 
- Pois, seu Mundinho, esse ano é cacau de dar gosto. O que vosmicê precisa é aparecer lá na fazenda. Passar uns dias com a gente. É casa de pobre, mas, se vosmicê quiser dar a honra, não vai morrer de fome, graças a Deus. Pra ver as roças carregadinhas, tudo luzindo nos pés. Tou começando a colher... Dá alegria aos olhos ver essa fartura de cacau.

O exportador batia na perna do fazendeiro:

- Pois aceito seu convite. Vou passar um desses domingos com o senhor...

- Venha no sábado, domingo os homens não trabalham. Volta na segunda-feira. Se quiser, é claro, a casa é sua...

- Trato feito, sábado lá estarei. Agora já posso sair um pouco, estava amarrado aqui com essa história da vinda do engenheiro.

- Diz que o moço chegou, é mesmo verdade?

- Verdade verdadeira, coronel. Amanhã já estará mexendo na barra. Prepare-se para ver em breve o cacau de suas fazendas saindo direto de Ilhéus para a Europa, para os Estados Unidos...

- Sim, senhor. Quem houvera de dizer... - sorveu outro gole de licor, espiava Mundinho com seus olhos sabidos. - De primeira, essa cachaça, coisa fina. Não é daqui, pois não?

- mas sem esperar resposta continuou:

- Diz que também vosmicê vai ser candidato nas eleições? Me contaram essa novidade, fiquei sem acreditar.

- E por que não, coronel? - Mundinho estava contente com o velho ter entrado no assunto.

- Será que não tenho nenhuma qualidade? Pensa assim tão mal de mim?

- Eu? Pensar mal de vosmicê? Deus me livre e guarde. Vosmicê é mais que merecedor. Só que... - suspendia o cálice de licor, expondo-o ao sol. - Só que vosmicê, como essa cachaça, não é daqui... - elevava os olhos para Mundinho, a espiá-lo.

O exportador balançou a cabeça: aquele argumento não era novo, já se acostumara. Rebatêlo tornara-se um hábito, uma espécie de exercício intelectual:

- O senhor nasceu aqui, coronel?

- Eu? Sou de Sergipe, sou ladrão de cavalo como dizem esses moleques daqui, examinava os reflexos do cristal ao sol. - Só que já faz mais de quarenta anos que arribei em Ilhéus.

- Eu tenho somente quatro anos, quase cinco. E sou tão grapiúna como o senhor. Daqui não vou mais sair (AMADO, 1960, p. 194-195).

$\mathrm{Na}$ descrição do personagem, que encarna o novo no romance em inúmeras de suas passagens, vê-se alguém revolucionário e tradicional, ao mesmo tempo. Eis um achado de Jorge Amado: entregar ao tradicional, ao bucólico, traços de uma revolução microscópica, mas envolvente, onde o velho e o novo convivem como síntese de um Brasil que nasce híbrido, e híbrido se faz, para além de maniqueísmos.

Afinal, os indivíduos são criação permanente da dimensão histórico-social de uma sociedade. É assim que temos que ver e entender os coronéis, mistura de empreendedorismo e administração. Eles foram socialmente produzidos, e expressam bem seu espaço-tempo. Eles estão presentes de forma extraordinária com sua carga dramática na obra de Jorge Amado, que lhes dá expressão. Mais do que isso, permite que observemos como eles se perpetuam em novas instituições imaginarias. Elas portam o velho em seu seio. 
Ainda sobre Mundinho Falcão, o personagem inaugura um novo momento para a Ilhéus daquela época, assentado na ideia de progresso, na valorização da educação, do pioneirismo, do empreendedorismo. Sua intervenção na cidade se dá de forma carismática e estratégica. Ele não se impõe pela força e pelas armas, mas conquista terreno e autoridade por meio de suas ideias e de sua capacidade de fazer acontecer, de transformar a olhos vistos o seu redor, de ajudar a operar, de renovar instituições imaginárias sociais.

O Doutor, admirador de Mundinho, atalhou:

- De homens como Mundinho Falcão é que estamos precisando. Homens de visão, corajosos, dispostos...

- Ora, Doutor, coragem é que nunca faltou aos homens dessa terra...

- Não falo disso: dar tiro e matar gente. Falo de coisa mais difícil...

- Mais difícil?

- Mundinho Falcão chegou aqui outro dia, como diz Amâncio. E veja quanta coisa já realizou: abriu a avenida na praia, ninguém acreditava, foi um negócio de primeira, e, para a cidade, uma beleza.

Trouxe os primeiros caminhões, sem ele não saía o Diário de Ilhéus nem o Clube Progresso.

- Dizem que emprestou dinheiro ao russo Jacob e a Moacir para a empresa de marinetes...

- Estou com o Doutor - disse o Capitão até então silencioso. - De homens assim é que precisamos... Capazes de compreender e ajudar o progresso (AMADO, 1960, p. 353).

As novas instituições de que fala Jorge Amado, são os novos conceitos de poder. Entre eles, podemos destacar um ótimo círculo de influência que não se limita ao local e nem às redondezas. Outro conceito importante no romance é a presença de um amor romântico que poderia unir homens e mulheres, tipo de amor até então desconhecido pelo machismo vigente no sul da Bahia. Mundinho vem do Rio de Janeiro, de uma família de políticos e pessoas letradas. Não se trata de um caipira, rude e violento, como os outros personagens da trama ou mesmo Ramiro Bastos, seu rival durante todo o romance.

Mundinho representa o novo, mas não a ruptura. Ele representa e explicita a dinâmica sócio-histórica, na medida em que é criação e criatura. Participa do imaginário instituinte, já que ele institui novas significações imaginárias sociais. Ele representa a passagem de uma forma de administração tradicional para uma administração moderna. Trata-se do novo, por refazer o velho, mas não se trata de destruí-lo, aniquilá-lo por completo. Podemos dizer que as instituições imaginárias da velha Ilhéus não morrem, mas se reinventam, sobrevivem no novo. Transformaram-se de forma híbrida, mesclando a dominação tradicional, com o carisma, o empreendedorismo, a inovação e a capacidade de transformar.

Em resumo, o que Jorge Amado descreve como o mundo social da velha Ilhéus, seu hibridismo, sua renovação de poder que engloba o velho é em si o imaginário social instituinte que podemos prolongar para efeitos analíticos do campo da Administração no Brasil. Muitas modernizações no âmbito da Administração e das organizações no Brasil são realidades dentro dessa dinâmica sócio-histórica. Elas contêm, de forma exacerbada, a tensão criativa entre o velho e o novo. Do nascimento do novo ali, datado socialmente, vemos o elemento sócio-histórico claramente presente nas origens da Administração no Brasil.

Além disso, em Gabriela, cravo e canela, Jorge Amado descreve de forma brilhante a flexibilidade dos sistemas políticos brasileiros que se modificam e se transformam sem romper, sem destruir o paradigma anterior. Ao assim proceder, eles eliminam muito da dinâmica sócio-histórica, efetuando sempre o movimento da assimilação, transformação e síntese, evitando a tensão radical que poderia aniquilar o velho. 
Essa é a essência da história das instituições imaginárias da Administração no Brasil, da sua dinâmica sóciohistórica. Como instituição imaginária, está presente até os nossos dias de hoje. Essa dinâmica sóciohistórica se coloca nas dimensões macro e micro, sobretudo nas elites. O imaginário instituinte - referenciais de moderno no campo da Administração pública e privada - brota do coronel como empreendedor e administrador, de suas práticas. Uma vez instituído, a lógica da tensão criativa do coronel empreendedoradministrador produz resultados no mundo de todos. As práticas dos personagens de Jorge Amado mostram muito bem isso.

Seu Mundinho, todo esse tempo combati o senhor. Fui eu quem mandou tocar fogo nos jornais - sua voz macia, seu único olho e as palavras claramente pronunciadas como se resultassem de longa reflexão. - Fui eu também quem mandou atirar em Aristóteles.

Acendeu um cigarro, continuou:

- Estava preparado para virar Ilhéus pelo avesso. Pela segunda vez. Quando eu era mais moço, em companhia do compadre Ramiro, tinha virado uma primeira vez - parou como a recordar. - Os jagunços estavam de atalaia, prontos para descer. Os meus e os de outros amigos. Para acabar com a eleição - olhou com seu olho são para o exportador, sorriu. Havia um cabra, bom na pontaria, meu conhecido velho, determinado para o senhor.

Mundinho ouvia muito sério. Amâncio pitou o cigarro:

- Agradeça estar vivo ao compadre, seu Mundinho. Se ele não tivesse morrido, quem estava no cemitério era o senhor. Mas Deus não quis, chamou ele primeiro.

Silenciou, talvez a pensar no amigo desaparecido. Mundinho esperou, um pouco pálido.

- Agora tudo acabou. Fiquei contra o senhor porque para mim o compadre era mais que um irmão, era como se fosse meu pai. Nunca me importei de saber quem tinha razão. Pra quê? O senhor estava contra o compadre, eu estava contra o senhor. E, se ele fosse vivo, eu estava com ele contra o diabo em pessoa (AMADO, 1960, p. 264).

Em Ilhéus anterior a Mundinho, o medo se impunha pelo poder das armas e pela ameaça da morte eminente. No novo momento, o que se impõe é a modernidade, mesmo que prenhe do velho. Quem estiver fora dela está sob a ameaça de ficar para trás, de cair no ostracismo, de ser atropelado pela inovação. O que esses personagens da literatura nos trazem são exemplos e por que não, padrões, de um universo imaginário híbrido, onde são produzidos diversos processos simultâneos de transformação, mudança, conflito e tradição. Podemos, neles, ver claramente como o elemento sócio-histórico é instituído e instituinte em sua plena operação de produção de instituições imaginárias sociais.

\section{Conclusão}

Esta pesquisa buscou aproximar o campo da Administração da produção teórica de Castoriadis ao analisar um romance de Jorge Amado a partir do conceito de sócio-histórico aplicado ao mundo do trabalho e da Administração. A matriz analítica proporcionada pela teoria de Castoriadis nos fornece lentes analíticas poderosas e refinadas, qualificando nossa compreensão do processo sócio-histórico e nos ajudando a elucidar os padrões de Administração no Brasil.

Ao longo da análise, destacamos as incoerências que podem emergir da adoção de práticas administrativas sem a devida consideração da dimensão sócio-histórica e desenvolvemos a ideia do coronel como eixo interpretativo para entender o imaginário social da Administração no Brasil. Com efeito, no momento chave da modernização brasileira, quando a República permite uma democratização, mesmo que precária, do poder antes centrado no Imperador e em sua Corte, ganha destaque o coronel republicano como empreendedor- 
administrador. Como produto de todo um processo sócio-histórico, ele nasce já investido dos elementos que constituem o Brasil. Assim, cada coronel que administra uma organização produtora de café, cacau, algodão, borracha ou qualquer outra riqueza agrícola fundamental no novo Brasil republicano, porta o Brasil. Porta suas instituições imaginarias centrais.

A principal contribuição da pesquisa para o avanço do conhecimento na área de Administração e de Estudos Organizacionais é a provocação que decorre de nossa análise e a proposição do referencial de Castoriadis como caminho analítico rico e fecundo para se sofisticar a pesquisa e a prática organizacional. A integração da teoria de Castoriadis pode qualificar a análise organizacional ao favorecer uma compreensão histórica dos fenômenos organizacionais e administrativos. Entretanto, vai muito além disso, ao propor uma compreensão que é dinâmica - não simplista, linear, mecânica ou determinista - da história e das construções sociais.

A integração do referencial teórico de Castoriadis no campo da Administração permite análises que não se reduzem a explicações dos fenômenos sociais com base na prescrição e na lógica conjuntista-identitária. Com isso, o conceito de sócio-histórico permite integrar questões individuais e societais, instituído e instituinte, no processo dinâmico que é a Administração. O sócio-histórico como tensão criativa permite o desenvolvimento de lentes analíticas que captam essa tensão na Administração como campo de prática profissional e como campo de produção teórica.

Por exemplo, a consideração do conceito de sócio-histórico permite aos administradores serem mais precavidos e assertivos em suas tomadas de decisão. Ou seja, antes de se adotar e difundir qualquer modismo gerencial, é necessário refletir sobre o que ele porta do sócio-histórico. Não podemos embarcar cegamente nos automatismos dos modismos e nem em códigos copiados de outros contextos. Pela desconsideração inconsequente do elemento sócio-histórico da Administração, muitas vezes, planos de gestão podem se tornar idealizações politicamente perigosas, que não costumam produzir os efeitos almejados.

Outra repercussão da pesquisa se traduz em termos metodológicos. O romance se revelou uma fonte inestimável de informação e de inspiração para a condução desta pesquisa. A riqueza de detalhes e nuanças, tanto de contexto como de padrões relacionais, permitiu uma melhor compreensão de como a teoria de Castoriadis pode ser mobilizada no contexto de uma sociedade como a brasileira. Com isso, acreditamos que a leitura mais profunda das grandes obras literárias sempre nos permitirão conclusões importantes de determinado tempo social. Elas nos permitem elucidar a presença da dinâmica sócio-histórica na constituição da sociedade.

O chamado romance regional, que tem expressões nas obras de Jorge Amado, Érico Veríssimo, José Lins do Rego, José Américo, Wilson Lins ou Guimarães Rosa retrata com tanta força os personagens que mobilizam os processos administrativos e atividades empreendedoras, remetendo não só para a história, mas também para um imaginário administrativo e organizacional repleto de subserviência, alianças, resistências, desmandos e outros fenômenos tão importantes para entender a Administração como prática.

Ao resgatar o universo construído na literatura de Jorge Amado, em especial o recorte feito em relação ao personagem Mundinho Falcão, nos resta algumas indagações. Mesmo sendo um romance escrito há mais de 50 anos, não nos parece que algumas práticas e as transformações ocorridas ainda soam muito familiares com alguns padrões relacionais da sociedade brasileira contemporânea? Se assim o for, parece razoável supor que esse percurso pode e dever ser feito para uma melhor compreensão dos padrões de gestão das organizações de hoje. A instituição imaginária da sociedade não muda radicalmente todos os dias, a todo momento. Por isso, não buscamos entender o coronel como um elemento do passado, mas, sobretudo, como personagem que emerge do nosso processo sócio-histórico. Portanto, não está preso ao passado, mas reinventando-se a cada momento. Teve papéis diferentes no tempo, mas também institui valores no campo da gestão de pessoas e processos que ainda estão vivos.

Agora que sabemos que o sócio-histórico é tensão criativa, somos conduzidos a refletir sobre como aplicar essa categoria analítica em outras escalas territoriais, como regiões, estados ou cidades. Outra pista para pesquisas futuras se expressa no movimento de intensificação dos processos de glocalização (DRORI, 
HOLLERER e WALGENBACH, 2013) e de interculturalidade (CHANLAT, DAVEL e DUPUIS, 2013), indicando uma diversidade de tensões opostas que recai sobre as sociedades e indivíduos contemporâneos. Entendemos que esse contexto suscita novas investigações para melhor entender como as tensões criativas acontecem em organizações que valorizam tanto o global quando o local, tanto suas origens históricas como novos referentes culturais oriundos de outras nacionalidades ou regiões. Ficamos na expectativa de que nossa pesquisa possa estimular uma melhor valorização dos olhares dinâmicos que os pesquisadores podem desenvolver sobre a propulsão sócio-histórica de nossas organizações de hoje e do futuro.

\section{Referências}

AMADO, J. Gabriela, cravo e canela. Lisboa: Europa-América, 1960.

CALDEIRA, J. História do Brasil com empreendedores. São Paulo: Mameluco, 2009.

CASTORIADIS, C. A instituição imaginária da sociedade. Rio de Janeiro: Paz e Terra, 1982.

CASTORIADIS, C. Socialismo ou barbárie: o conteúdo do socialismo. São Paulo: Brasiliense, 1983.

CASTORIADIS, C. As encruzilhadas do labirinto: o mundo fragmentado. São Paulo: Paz e Terra, 1992. v. 3.

CASTORIADIS, C. As encruzilhadas do labirinto: os domínios do homem. Rio de Janeiro: Paz e Terra, 2002a. v. 2.

CASTORIADIS, C. As encruzilhadas do labirinto: a ascensão da insignificância. São Paulo: Paz e Terra, 2002b. v. 4.

CASTORIADIS, C. As encruzilhadas do labirinto: figuras do pensável. São Paulo: Paz e Terra, 2004. v. 4.

CASTORIADIS, C.; COHN-BENDIT, D. Da ecologia à autonomia. São Paulo: Brasiliense, 1981.

CHANLAT, J.-F. Ciências sociais e management: reconciliando o econômico e o social. São Paulo: Atlas, 1999.

CHANLAT, J. F.; DAVEL, E.; DUPUIS, J.-P. (Eds.). Cross-cultural management: culture and management across the world. New York: Routledge, 2013.

CURTIS, D. A. The Castoriadis reader. Oxford: Blackwell, 1997.

CZARNIAWSKA-JOERGES, B.; GUILLET DE MONTHOUX, P. Good novels, better management reading organizational realities. Chur, Switzerland: Harwood, 1994.

DE COCK, C.; REHN, A.; BERRY, D. For a critical creativity: the radical imagination of Cornelius Castoriadis. In: CHAN, J.; THOMAS, K. (Eds.). Handbook of research on creativity. London: Edward Elgar, 2013. 150-161 p.

DRORI, G. S.; HOLLERER, M. A.; WALGENBACH, P. Global themes and local variations in organization and management: perspectives on glocalization. London: Routledge, 2013.

FAORO, R. Os donos do poder: formação do patronato político brasileiro. 2. Ed. Porto Alegre: Editora Globo, 1975.

FERREIRA, F. V. Management no Brasil em perspectiva histórica: o projeto do IDORT nas décadas de 1930 e 1940. 254 f. Tese (Doutorado em Administração) - Escola de Administração de Empresas de São Paulo, Fundação Getulio Vargas, São Paulo, 2008.

FREYRE, G. Casa grande e senzala. Rio de Janeiro: José Olympio, 1966.

FREYRE, G. Sobrados e mudambos: decadência do patriarcado rural e desenvolvimento do urbano. 4. ed. Rio de Janeiro: José Olympio, 1968. 
GALVÃO, A. L. M. O coronelismo nas narrativas de Wilson Lins: espaços de poder. 120 f. Dissertação (Mestrado em Literatura e Diversidade Cultural) - Universidade Estadual de Feira de Santana, Feira de Santana, 2010.

GAUlEJAC, V. D. Approche socio-psychologique des histoires de vie. Éducation Permanente, v. 72, n. 3, p. 33-45, 1984.

JOAS, H.; MEYER, R. Institutionalization as a creative process: the sociological importance of Cornelius Castoriadis's political philosophy. The American Journal of Sociology, v. 94, n. 5, p. 1184-1199, 1989.

KLOOGER, J. Castoriadis: psyche, society, autonomy. Leiden: Brill, 2009.

KOMPOROZOS-ATHANASIOU, A.; FOTAKI, M. Creativity in organizations: introducing the radical imagination of Cornelius Castoriadis. In: KENNY, K.; FOTAKI, M. (Eds.). The psychosocial in organization studies: affect at work. London: Palgrave MacMillan, 2014. 60-82 p.

MOTTA, F. P. Controle social nas organizações. Revista de Administração de Empresas, v. 33, n. 5, p. 68-87, 1993.

PAES DE PAULA, A. P. Tragtenberg revisitado: as inexoráveis harmonias administrativas e a burocracia flexível. Revista de Administração de Empresas, v. 41, n. 3, p. 77-81, 2001.

PATIENT, D.; LAWRENCE, T.; MAITLIS, S. Understanding workplace envy through narrative fiction. Organization Studies, v. 24, n. 7, p. 1015-1044, 2003.

PHILLIPS, N. Telling tales: on the role of narrative fiction in organizational analysis. Organization Studies, v. 16, n. 4, p. 625-649, 1995.

REED, M. Organizational theorizing: a historically contested terrain. In: CLEGG, S. R. et al. (Eds.). Handbook of organization studies. London: Sage, 1996. 31-56 p.

RODRIGUES, H. D. B. C. Cura, culpa e imaginário radical em Cornelius Castoriadis: percursos de um sociobárbaro. Psicologia USP, v. 9, n. 2, p. 87-138, 1998.

TRAGTENBERG, M. Administração, poder e ideologia. São Paulo: Moraes, 1980.

VASCONCELLOS, J. G. M. A invenção do coronel. Vitória: Ed. UFES, 1995.

VASCONCELLOS, J. G. M. O coronelismo nas organizações: a gênese da gerência autoritária brasileira. In: DAVEL, E.; VASCONCELLOS, J. G. (Eds.). "Recursos" humanos e subjetividade. 4. ed. Petrópolis: Vozes, 2002. $220-231$ p.

VERGARA, S. C. A hegemonia americana em estudos organizacionais. Rev. Adm. Pública, v. 35, n. 2, p. 63-77, 2001. 